\title{
OIL-CONTAMINATED WATER TREATMENT WITH MODIFIED ASH WOOD SAWDUST
}

\section{Irina Iakovlevna Sippel ${ }^{1}$ (D), Gulnaz Albertovna Akhmetgaleeva ${ }^{2}$}

\footnotetext{
${ }^{1}$ Associate Professor, Department of Chemistry and Ecology, Naberezhnye Chelny Institute, Kazan Federal University, Kazan, Russia.

${ }^{2}$ Master's Degree Student, Department of chemistry and ecology, Naberezhnye Chelny Institute, Kazan Federal University, Kazan, Russia.
}

Received - September 25, 2020; Revision - November 13, 2020; Accepted - December 11, 2020

Available Online December 15, 2020

DOI: http://dx.doi.org/ 10.18006/2020.8(Spl-2-AABAS).S280.S285

\section{KEYWORDS}

Oil Product

Woodworking Waste

Sorption Capacity

Ultrasonic Treatment

Ash Sawdust

\section{* Corresponding author}

E-mail: irina.sippel@yandex.ru (Irina Iakovlevna Sippel)

Peer review under responsibility of Journal of Experimental Biology and Agricultural Sciences.

Production and Hosting by Horizon Publisher India [HPI] (http://www.horizonpublisherindia.in/).

All rights reserved.

\begin{abstract}
In the current scenario treatment of oil hydrocarbons contaminated surface and water is one of the most critical environmental issues. Although various treatment methods are available, among these the most effective and environmentally friendly is the sorption method of treatment. The current study is an attempt to investigate the sorption capacity of native and ultrasonically modified ash sawdust sorbents to dissolved and emulsified oil hydrocarbons from wastewater and water bodies under dynamic conditions. Further, ash sawdust (Fraxinus excelsior) formed in woodworking enterprises of the Kama region, Republic of Tatarstan, was used as sorbents. To increase the sorption capacity, wood waste was exposed to ultrasound at a frequency of $35,000 \mathrm{~Hz}$ for 4 hours. Results of the study revealed that wood waste has sorption capacity and sorption oil hydrocarbons from wastewater were dependent on various factors. Further, the ultrasonic treatment of wood waste has been increased the sorption capacity of wood waste by 24 percent. Under dynamic conditions, the sorption capacity of ultrasound modified ash sawdust with relation to emulsified oil products was investigated, and reported that ash sawdust has $79 \%$ cleaning efficiency. The toxicity of ultrasound-modified ash sawdust was investigated by bio testing on Daphnia magna straus and reported that the ultrasound-modified ash sawdust has acute toxicity on experimental organisms.
\end{abstract}

All the articles published by Journal of Experimental Biology and Agricultural Sciences are licensed under a Creative Commons Attribution-NonCommercial 4.0 International License Based on a work at www.jebas.org.

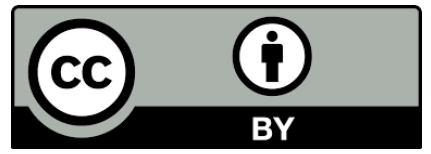




\section{Introduction}

Oil spills are a general problem and it usually occurred due to the escape of oil from crude oil confinement, extraction, transportation, and processing of oil. Various water bodies throughout the world are polluted with different hydrocarbon fractions. Under aquatic environment, petroleum hydrocarbons undergo various processes of migration and transformation, including dissolution of low molecular weight components, emulsification, evaporation of volatile fractions, photochemical oxidation, and finally biodegradation of oil spilled into the sea under the action of certain types of microorganisms. The cleanup of these oil spills is dependent on various recovery methods such as biological, mechanical, and physical methods. Mechanical and physical methods have various limitations and currently, the most promising method is the biological method. Among the various biological methods, the use of sorption is the most favored procedure for cleaning oil-spill because of its low cost. Uses of organic waste such as waste from agricultural, food and woodworking industries as sorption materials are not only cost-effective but also have high sorption capacity, and are environmentally friendly, and easily disposable. Further, various cellulose-containing wastes such as substandard grain, rice, buckwheat, barley, wheat husks, straw, cake, sawdust, walnut shells, coconut, almonds, onion husks, flax fire, leaf litter can be used as sorption materials (Ibrahim et al., 2010; Ofomaja et al., 2010; Fu \& Chung, 2011; Wang, 2013; Wahi, 2013; Nagy et al., 2014; Stepanova, 2014; Kharlyamov et al., 2014; Yusupova, 2015; Zolgharnein, 2015; Balintova et al., 2016; Denisova et al., 2016; Denisova et al., 2017; Sippel \& Akhmetgaleeva, 2019a). To improve the sorption characteristics of biopolymeric waste, various chemical methods and physical exposure have been proposed, among this, treatment with organic substances, solutions of alkalis, acids, hydrogen peroxide, thermal and ultrasonic exposure are the most common one. Further, modified cellulose-containing wastes can be effective sorbents concerning oil, oil products, heavy metal ions and other pollutants (Ofomaja et al., 2010; Ibrahim et al., 2010; Wang, 2013; Nagy et al., 2014; Stepanova, 2014; Kharlyamov et al., 2014; Denisova et al., 2016; Denisova et al., 2017; Sippel, 2019b).

In the current study, the sorption properties of ash sawdust (Fráxinus excélsior) concerning dissolved in water and emulsified oil hydrocarbons are studied. Ash wood is generally used for construction, decoration, furniture, stairs, crafts, toys, and carvings making. During the wood processing, a significant amount (5 to $50 \%$ ) of waste is generated; this amount is depending on the type of wood use (Ofomaja et al., 2010). Unlike lump waste, which has a relatively wide range of uses (from the production of small sawn timber and glued blanks to wood-chemical products), soft waste (sawdust, shavings, bark) is of limited use and is buried at industrial waste landfills.

The use of ash sawdust as an adsorbent could be an excellent alternative to mitigate the contamination and remedy the places of the spill for the sorption of oil. These bio adsorbents are a good source of cellulose and hemicellulose and lignin. In this regard, the use of ash sawdust as an effective, cheap, environmentally friendly sorption material seems to be promising. This study aims to evaluate the sorption properties of ash sawdust, to clean up oil spills while taking into consideration various factors.

\section{Materials and Methods}

Ultrasonic modification in wood waste was carried out according to the method described by Sippel \& Akhmetgaleeva (2019a). Initially, this sorption material was sonicated in distilled water at a frequency of $35 \mathrm{kHz}$ for predecided periods at a temperature of $25^{\circ} \mathrm{C}$. After processing, the sawdust was thoroughly washed with distilled water to completely remove colored and water-soluble substances and drying it at $70^{\circ} \mathrm{C}$ to gain constant weight.

To determine the sawdust adsorption capacity with relation to dissolved oil products, a model solution was prepared by mixing oil and distilled water using a mechanical stirrer. Then the suspended oil was separated from the liquid and the solution was settled until the complete separation of the aqueous and organic phases. In the resulting model solution, the concentration of dissolved petroleum products was determined by IR spectroscopy using a KN-3 analyzer-concentration meter.

To determine the adsorption capacity of ash wood, $50 \mathrm{~cm}^{3}$ of the model solution containing dissolved petroleum products, and $1 \mathrm{~g}$ of sawdust were placed in $250 \mathrm{~cm}^{3}$ conical flasks. Then the contents of the flasks were vigorously stirred for various time periods (from 15 to 180 minutes). After a certain time, the ash sawdust was separated from the solution by filtration through a paper filter. The residual amount of petroleum products in the filtrate was determined by IR spectroscopy. The adsorption value of oil products A ( $\mathrm{mg} / \mathrm{g})$ was calculated by the formula:

$A=\frac{\left(C_{u c x}-C_{\kappa}\right)}{m} \cdot V$

$C_{\text {in }}$ - initial concentration of oil product in the model solution $\left(\mathrm{mg} / \mathrm{dm}^{3}\right)$,

$C_{\text {fin }}$ - final concentration of oil product in the solution $\left(\mathrm{mg} / \mathrm{dm}^{3}\right)$,

$m$ - sample mass (g),

$V$ - model solution volume $(\mathrm{dm})^{3}$

To study oil absorption under dynamic conditions, a laboratory plant consisting of a supply and receiving container having a prepared solution and a filter column with the tested sorbent was assembled. The layout of the laboratory plant for this dynamic adsorption study is similar to that described by Yusupova (2015). 
Initially, model solutions of various concentrations (50, 100, and $250 \mathrm{mg} / \mathrm{dm} 3$ ) were prepared in a separate container with emulsified oil products. For this purpose, the required amount of oil was mixed with distilled water in the presence of surfactants. The required water flow rate was set and passed through a glass column filled with the tested ash sawdust. The height of the sawdust layer was 0.1 and $0.2 \mathrm{~m}$. Water samples from the column outlet were taken at regular intervals $(15,30,60,120,180$ minutes), and the residual content of oil products in the water was determined by IR spectroscopy.

The sawdust toxicity was determined by the bio-testing method following the method for measuring the amount of Daphnia magna Straus by direct counting (PNDFT 14.1:2:3:4.12-06, T 16.1:2:2.3:3.9-06, 2014). This technique is based on determining the mortality of daphnia when exposed to toxic substances present in the analyzed water when compared with a control sample, which does not contain harmful substances. The mortality of daphnia in the studied and control sample was taken into account at every 24 hours intervals; collected information suggested that not more than $50 \%$ of daphnia have died in all dilutions of the tested water.

To determine the toxicity of the analyzed aqueous extracts, the percentage of daphnia died in the tested water (A, \%) was compared with the control sample:

$X_{\mathrm{c}}$ is the number of daphnia that survived in the control sample;

$$
A=\frac{X_{K}-X_{T}}{X_{K}} \cdot 100 \%
$$

$X_{\mathrm{T}}$ is the number of daphnia that survived in the tested aqueous extract.

At $\mathrm{A} \leq 10 \%$, the tested aqueous extract has no acute toxic effect.
This percentage of dead daphnia was used to calculate the harmless dilution ratio of the tested waters. At $\mathrm{A} \geq 50 \%$, the analyzed aqueous extract has an acute toxic effect. This value is used to determine the average lethal ratio of dilution of the test waters and to establish the hazard class of waste.

\section{Results and Discussion}

Ash sawdust (Fráxinus excélsior), formed as waste at one of the woodworking enterprises in Naberezhnye Chelny, Republic of Tatarstan, was used as a biosorption material in the current study. Sieve analysis of woodworking wastes showed a different fractional composition of sawdust, and the most massive fraction is particles with a size of 1-2 mm. The sorption capacity of native and ultrasound-modified ash sawdust was determined with dissolved and emulsified oil hydrocarbons. Further, adsorption of dissolved hydrocarbons from oil was carried out under static conditions using 4 hours of sonicated native ash sawdust. The kinetic relationships of the adsorption value of dissolved petroleum products by the original and modified samples are shown in Figure 1.

At the initial stage of adsorption, when the concentration of the adsorptive in the solution is maximum; the adsorption rate is highest and continues to increase until the adsorbent surface is completely saturated with adsorbate molecules. As the surface of the sorption material is saturated with adsorbate, the desorption rate was increased, and the adsorption equilibrium is gradually established. It was shown that the efficiency of purification from soluble oil hydrocarbons was $67.7 \%$ for native ash sawdust and $83.1 \%$ for sawdust subjected to ultrasonic modification for 4 hours.

In the case of model solutions, the possibility of purifying wastewater containing emulsified oil products was investigated.

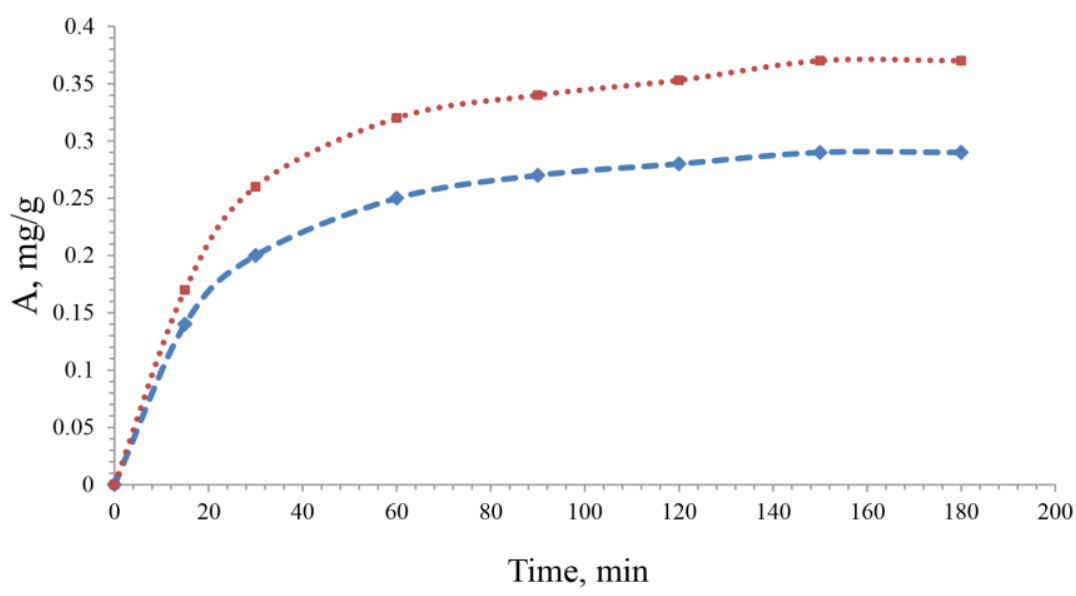

$\rightarrow-1 \quad \cdots \cdots 2$

Figure 1 Kinetic relationships of the adsorption value of dissolved petroleum products by the original (1) and modified (2) ash sawdust. 
The experiment was carried out under dynamic conditions using ultrasonically modified ash sawdust as a column media. Figure 2 shows the relationship between the concentrations of oil at the outlet of the sorption column to the initial concentration of the model solution $\mathrm{C} / \mathrm{C}_{0}$ on the volume passed solution $\mathrm{V}$. In case of a higher initial concentration of oil products in the model solution, the equilibrium state is reached faster.

Relationships in Figure 2 show that the post-treatment concentration of oil products quickly reaches the initial values, and the cleaning efficiency is $79 \%$. The obtained result is natural because the dynamic activity of sorption materials is always lower than the static one. For activated carbon, the dynamic activity is $85-95 \%$ of the static one in industrial-type adsorbents; for silica gel, the dynamic activity is $60 \%$ lower than the static one.

One of the most important requirements for sorption materials to treat water bodies from various pollutants is their high ecological purity, including the safety of the sorbent itself and the avoidance of secondary pollution during its use. To assess the ecological safety of modified ash sawdust, their toxicity was studied by biotesting for the lethality of the Daphnia magna Straus test object for a certain period. The results of the toxicity study are presented in Table 1. All dilutions after 48 hours show zero toxicity; an undiluted sample after 48 hours showed $10 \%$ mortality to daphnia, which indicates chronic toxicity.

The harmless multiplicity of dilution of aqueous extracts, which causes death not more than $10 \%$ of daphnia in 48 hours (BKR10-
48), for the ash sawdust understudy is:

$$
\mathrm{BKR}_{10-48}=10^{\frac{(\lg 10-\lg 1)(0,1-0,1)}{0,1}+\lg 1}=10^{0}=1
$$

According to the hazards materials classification criteria developed by the Ministry of Natural Resources and Environment, Russian Federation No. 536 dated 04th December 2014, the lethality of the ash sawdust belongs to class $\mathrm{V}$ of hazard materials. Modified ash woodworking wastes are practically non-hazardous, and their use as sorption materials will not cause secondary pollution of the hydrosphere. Waste sorbents saturated with oil or oil products can be utilized by incineration to obtain heat and electric energy or by pyrolysis to obtain carbon-containing products.

Ash sawdust is a readily available promising cost-effective organic material for oil-spill cleanup. Furthermore, it was observed that ultrasonic exposure modified sorbents and enhances the surface sorption. These results are in agreement with the findings of Onwuka et al. (2018) and Jmaa \& Kallel (2019).

\section{Conclusion}

The sorption capacity of native and ultrasonically modified ash sawdust with respect to dissolved oil hydrocarbons under static conditions has been investigated. The ultrasonic treatment has been shown to increase the sorption capacity of wood waste by $24 \%$ in relation to dissolved oil hydrocarbons. The efficiency of

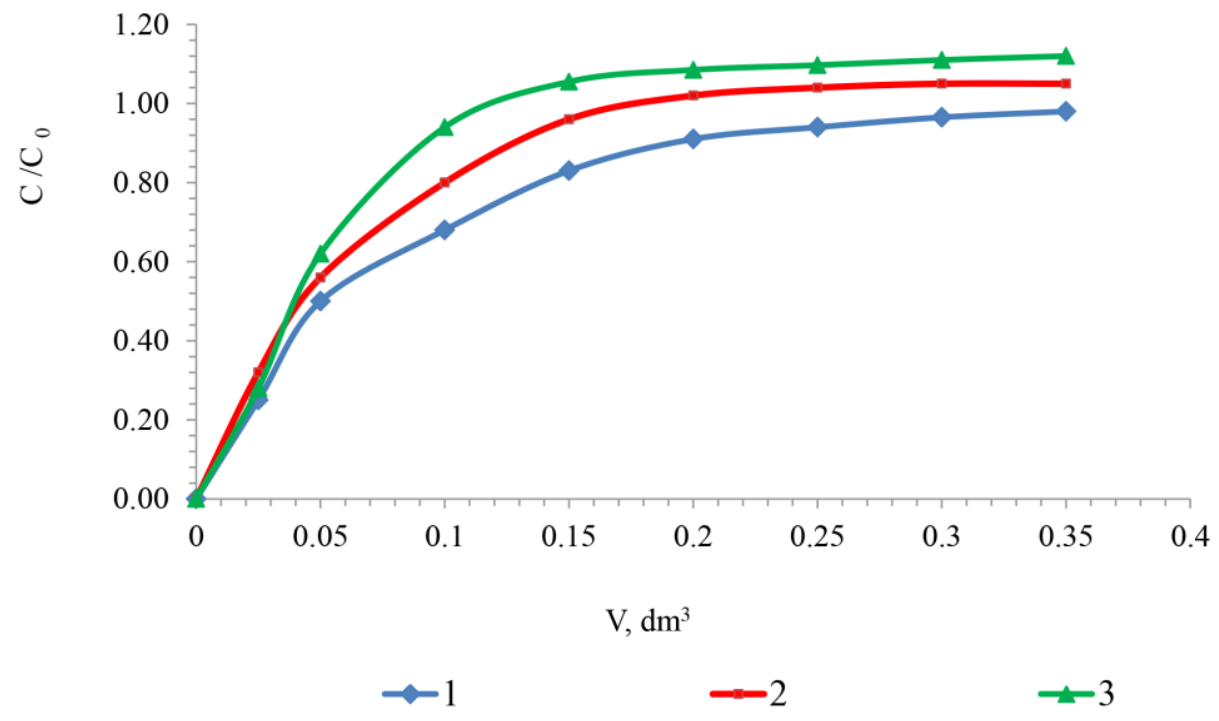

Figure 2 The relationship between the ratio of the concentration of oil at the outlet of the sorption column to the initial concentration of the model solution $\mathrm{C} / \mathrm{C}_{0}$ on the volume of the passed solution $\mathrm{V}\left(\mathrm{dm}^{3}\right)$ when using modified ash sawdust as a sorption medium and the initial concentration of oil products $\left(1-50 \mathrm{mg} / \mathrm{dm}^{3} ; 2-100 \mathrm{mg} / \mathrm{dm}^{3} ; 3-200 \mathrm{mg} / \mathrm{dm}^{3}\right)$. 
Table 1 Mortality of Daphnia magna Straus in water extracts out of ash (Fráxinus excélsior) sawdust residues

\begin{tabular}{|c|c|c|c|c|c|c|}
\hline \multirow{2}{*}{ Samples } & \multicolumn{5}{|c|}{ Mortality of daphnia, $\%$} & \multirow{2}{*}{ Toxicity } \\
\hline & 1 hour & 2 hours & 18 hours & 24 hours & 48 hours & \\
\hline Ash tree & 0 & 0 & 10 & 10 & 10 & chronic \\
\hline Ash tree $1: 10$ & 0 & 0 & 0 & 10 & 10 & chronic \\
\hline Ash tree 1:100 & 0 & 0 & 0 & 0 & 0 & absent \\
\hline Ash tree 1:1000 & 0 & 0 & 0 & 0 & 0 & absent \\
\hline Ash tree 1:10000 & 0 & 0 & 0 & 0 & 0 & absent \\
\hline Control sample & 0 & 0 & 0 & 0 & 0 & absent \\
\hline
\end{tabular}

ultrasound-modified ash sawdust sorption materials in the treatment of emulsified oil hydrocarbons was carried out under dynamic conditions by using a column medium and results of the study revealed $79 \%$ efficiency in emulsified oil products contaminated wastewater treatment. Further, the toxicity of the ultrasound-modified ash sawdust was determined by bio-testing and ash sawdust was classified as hazard class V waste, which suggested that the ash sawdust sorption will not lead to secondary pollution to the water bodies. These results suggested that ash sawdust can be used as an environmentally friendly, efficient, cheap and affordable sorption material for removing oil products from water environments. Further, ultrasonic exposure of ash sawdust enhances the efficiency of this sorption material and this is an environmentally safer method of increasing sorption capacity as compared to chemical modification.

\section{Acknowledgments}

The work is performed according to the Russian Government Program of Competitive Growth of Kazan Federal University.

\section{Conflict Of Interest}

Authors would hereby like to declare that there is no conflict of interests that could possibly arise.

\section{References}

Balintova M, Demcak S, Pagacova B (2016) A study of sorption heavy metals by natural organic sorbents. International Journal of Energy and Environment10: 189-194.

Denisova T, Shaikhiev I, Mavrin G, Sippel I, Kuznetsova N (2016) The influence of ash tree sawdust acid treatment on the removal of crude oil from water surfaces. Research Journal of Pharmaceutical, Biological and Chemical Science 7(5): 1742-1750.

Denisova TR, Shaikhiev IG, Nizameev IR, Mavrin GV, Sippel IY (2017)The influence of linden (tilia cordata) sawdust ultrasound treatment on oil sorption capacity and water uptake. Journal of Fundamental and Applied Sciences 9: 1798-1810.
FuY, Chung DDL (2011) Coagulation of oil in water using sawdust, bentonite and calcium hydroxide to form floating sheets. Applied Clay Science 53(4): $634-641$.

Ibrahim S, Wang S, Ang HM (2010) Removal of emulsified oil from oily wastewater using agricultural waste barley straw. Biochemical Engineering Journal 49:78-83.

Jmaa SB, Kallel A (2019) Assessment of Performance of Posidona oceanica (L.) as Biosorbent for Crude Oil-Spill Cleanup in Seawater. BioMed Research International Volume 2019, Article ID 6029654, 9 pages. DOI: https://doi.org/10.1155/2019/6029654.

Kharlyamov D, Mavrin G, Sippel I (2014) About the possibility of sorption concentration of heavy metals using magnetite. Life Science Journal 11(8): 607-610.

Nagy B, Mânzatu C, Măicăneanu A. et al. (2014) Effect of Alkaline and Oxidative Treatment on Sawdust Capacity to Remove Cd (II) from Aqueous Solutions: FTIR and AFM Study. Journal of Wood Chemistry and Technology 14: 301-311.

Ofomaja A, Naidoo EB, Modise J (2010) Surface modification of pine cone powder and its application for removal of $\mathrm{Cu}$ (II) from wastewater. Desalination and Water Treatment 14: 275-285.

Onwuka JC, Agbaji EB, Ajibola VO, Okibe FG (2018) Treatment of crude oil-contaminated water with chemically modified natural fiber. Applied Water Science 8:86. DOI: https://doi.org/10.1007/s13201-018-0727-5.

Order of the Ministry of Natural Resources and Environment of the Russian Federation No. 536 dated 04 ${ }^{\text {th }}$ December 2014 "About approval of criteria of wastes referral to I-V hazard classes by the degree of negative impact of the environment" Available at http://base.garant.ru/71296500/ access on $25^{\text {th }}$ April 2020.

PNDFT 14.1:2:3:4.12-06, T 16.1:2:2.3:3.9-06.

Methodology of measuremen to Daphnia magna Straus quantity to define toxicity of drinking, fresh natural and waste water, water extracts from ground, soils, sewage sludge, production and 
consumption waste by the method of counting forward. - M.: FBI"“Federal Centre of Analysis and Estimaiton: - 40 p.

Sippel IY, Akhmetgaleeva GA (2019a) Removal of petroleum products from water surface by chemically modified wood waste. Journal of Computational and Theoretical Nanoscience 16(12):5261 - 5264 .

Sippel IY (2019b) The Investigation of Wood Waste Ash and Linden as Sorbents of Petroleum Products. HELIX 9(4): 5170 5174.

Stepanova SV (2014) The investigation of sulfuric acid treatment influence on oil and water sorption capacity of oat processing wastes. Herald of Technological University 8: $228-231$.
Wahi R (2013) Oil removal from aqueous state by nature fibrous sorbent: An overview. Separation and Purification Technology 113: $51-63$.

Wang J (2013) Effect of kapok fiber treated with various solvents on oil absorbency. Industrial Crops and Products 40: 178-184,.

Yusupova A (2015) Treatment of wastewater containing heavy metal ions with sorbents and extracts from tannin-containing waste. Dissertation of the candidate of technical Sciences, Kazan: 35-36.

Zolgharnein J (2015) Hybrid central composite design optimization for removal of Methylene blue by Acer tree leaves: characterization of adsorption. Desalination and Water Treatment 54(9): 2601-2610. 